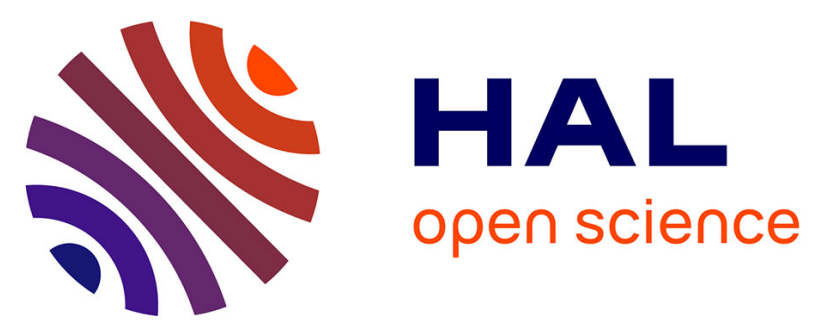

\title{
Internal stresses and carbon enrichment in austenite of Quenching and Partitioning steels from high energy $\mathrm{X}$-ray diffraction experiments
}

Sébastien Yves Pierre Allain, Steve Gaudez, Guillaume Geandier, Jean-Christophe Hell, Mohamed Gouné, Fréderic Danoix, Michel Soler, Samy Aoued, Angeline Poulon-Quintin

\section{To cite this version:}

Sébastien Yves Pierre Allain, Steve Gaudez, Guillaume Geandier, Jean-Christophe Hell, Mohamed Gouné, et al.. Internal stresses and carbon enrichment in austenite of Quenching and Partitioning steels from high energy X-ray diffraction experiments. Materials Science and Engineering: A, 2018, 710, pp.245-250. 10.1016/j.msea.2017.10.105 . hal-01667935

\section{HAL Id: hal-01667935 https://hal.science/hal-01667935}

Submitted on 2 Apr 2020

HAL is a multi-disciplinary open access archive for the deposit and dissemination of scientific research documents, whether they are published or not. The documents may come from teaching and research institutions in France or abroad, or from public or private research centers.
L'archive ouverte pluridisciplinaire HAL, est destinée au dépôt et à la diffusion de documents scientifiques de niveau recherche, publiés ou non, émanant des établissements d'enseignement et de recherche français ou étrangers, des laboratoires publics ou privés. 


\title{
Internal stresses and carbon enrichment in austenite of Quenching and Partitioning steels from high energy $\mathrm{X}$-ray diffraction experiments
}

Sébastien Yves Pierre ALLAIN ${ }^{1}$, Steve GAUDEZ ${ }^{1}$, Guillaume GEANDIER ${ }^{1}$, Jean-Christophe HELL ${ }^{2}$, Mohamed GOUNE ${ }^{3}$, Frédéric DANOIX ${ }^{4}$, Michel SOLER ${ }^{2}$, Samy Aoued ${ }^{3}$, Angeline Poulon-Quintin ${ }^{3}$

1 Institut Jean Lamour, UMR CNRS Université de Lorraine 7198, 54000 Nancy, France

2 Maizières Automotive Products, Arcelormittal Maizières Research SA, 57283 Maizières les Metz, France

3 Institut de Chimie de la Matière Condensée de Bordeaux, UPR CNRS 9048, 33608 Pessac, France

4 Normandie Université, UNIROUEN, INSA Rouen, CNRS, Groupe de Physique des Matériaux, 76000 Rouen, France

Corresponding author: sebastien.allain@univ-lorraine.fr; Tel.: +33-670-608-831

\section{Keywords:}

Steels; Q\&P; Synchrotron; Internal stresses; Austenite; Martensite

\begin{abstract}
:
Quenching and Partitioning (Q\&P) process permits to produce innovative microstructures containing large fraction of carbon enriched retained austenite. The present study highlights that austenite undergoes significant internal stresses generated during such thermal cycle. Both mechanical and chemical contributions are likely to affect its stability at room temperature and thus the resulting mechanical properties of the steel. The experiments carried out by High Energy X-Ray Diffraction (HEXRD) show unambiguously that internal stresses in austenite originate from martensitic transformation strain and from additional hydrostatic stresses induced during both reheating to partitioning temperature and final cooling. These eigenstrains are attributed to the difference in Coefficients of Thermal Expansion (CTE) between martensite and austenite and are predicted successfully with a purely elastic mean field approach. In the present study, retained austenite is shown to be in compression at room temperature. As a consequence, this state of stress contributes to stabilize retained austenite against a possible strain induced transformation at room temperature and affects the way to determine the carbon content in austenite.
\end{abstract}




\section{Introduction:}

Q\&P is a new annealing route proposed in 2003 to produce $3^{\text {rd }}$ Generation of Advanced High Strength Steels for automotive applications [1-3]. This two-step process leads to nanostructured duplex martensite/austenite microstructures with excellent balance between strength and formability. The high flow stresses of these steels are explained by the fine lamellar structure of the martensitic matrix (typical thickness of martensite blocks of laths around $200 \mathrm{~nm}$ ). They also show a high work-hardening rate and thus a good drawability thanks to a TRIP effect (TRansformation Induced Plasticity), i.e. a dynamical hardening due to the strain-induced transformation of austenite into martensite. The stability of austenite against a strain-induced transformation at room temperature is thus one of the key factors controlling the mechanical properties of these steels and must be designed with great care [4-6].

The stability of retained austenite in Q\&P steels, as in more conventional ferritic TRIP steels, depends on its local composition (mainly carbon content in the studied steels) [4] but also on its mechanical state (hydrostatic stresses) and its local micromechanical neighborhood (size and shape effects) [5]. Xiong et al. [6] have investigated using HEXRD a Q\&P steel containing two populations of retained austenite islands with high and low carbon contents respectively. When straining such steel, the strain induced martensitic transformation is surprisingly shown to occur in carbon rich films instead of films showing lower carbon content [6]. The authors have thus suspected a stabilizing effect of internal stresses due to the phase transformations to explain this unexpected result, when compared to other studies [4].

HEXRD [7] or neutron diffraction [8] have been used in the past to study in situ also phase transformations and carbon enrichment in austenite during Q\&P processes. Nevertheless, these prior studies are restricted to the partitioning step. In a previous paper [9], the authors have shown, using in situ HEXRD experiments, that austenite is not only enriched in carbon due to both partitioning and carbide-free bainitic transformation, but is also affected by successive mechanisms inducing internal stresses in austenite, confirming the views of Xiong et al. Along the Q\&P cycle, austenite undergoes first compressive hydrostatic stresses after the primary martensitic transformation, and tensile hydrostatic stresses due to eigenstrains at phase scale during final cooling. These eigenstrains of thermal origins are induced by the difference between the coefficients of thermal expansion (CTE) of martensite and austenite. They will be designated as thermal eigenstrains in the following. In this previous analysis, retained austenite was shown to undergo tensile hydrostatic stresses which favor a possible TRIP effect at room temperature (RT). On the other hand, carbon enrichment leads to austenite stabilization (against thermal and strain-induced transformation). These three contributions (phase transformation, carbon enrichment and thermal eigenstrains) affect the austenite lattice parameters and can solely be discriminated from in situ analysis. As a corollary, 
it must be admitted that the austenite carbon content of retained austenite should not be estimated solely from its lattice parameter at RT in these steels.

In this paper, the thermal eigenstrains are derived from mean field models, in order to predict the internal stresses during reheating and final cooling. The analysis conducted introduces for the first time the temperature dependence of the coefficient of thermal expansion (CTE) of unconstrained austenite [10,11]. The results achieved are based on new in-situ HEXRD experiments conducted at DESY synchrotron beamline in Hamburg [12]. Compared to our previous studies at ESRF, qualities of the thermal cycles have been improved while keeping the time-resolved quantification.

\section{Material and methods:}

The studied steel is a Fe-0.313C-2.44Mn-1.52Si (wt\%, as for all compositions given in this paper) model alloy, a chromium free version of the alloy studied previously by the authors $[9,13]$. The alloy has been prepared by Vacuum Induction Melting (VIM). $30 \mathrm{~mm}$ thick ingots were homogenized at $1250{ }^{\circ} \mathrm{C}$ for $16 \mathrm{~h}$ followed by hot rolling until $10 \mathrm{~mm}$ sheets were obtained. Finally, cylindrical samples ( $\Phi=4 \mathrm{~mm} ; 10 \mathrm{~mm}$ height) were machined in the central part of the sheets. The Ms value of the studied steel is $320{ }^{\circ} \mathrm{C}$ according to our in situ investigations. This value is consistent with Van Bohemen's model $\left(313^{\circ} \mathrm{C}\right)[14]$.

The HEXRD experiments were carried out on the DESY PETRA P07 beamline (Hamburg, Germany). The high-energy monochromatic beam ( $E=100 \mathrm{keV}, \lambda=0.13 \mathrm{~nm}$ ) allowed working in transmission mode. The association with a fast 2D Perkin-Elmer detector enabled high acquisition rates $(10 \mathrm{~Hz})$ needed to study time-resolved processes on bulk samples, especially during initial quenching and reheating. The detector was positioned about $1 \mathrm{~m}$ behind the sample, giving access to full Debye-Scherrer rings with a maximum $2 \theta$ angle of $12^{\circ}$. The experimental set-up is similar to the one used in $[9,13]$. The 2D diffraction patterns produced during the experiments were integrated circularly using Fit2D software (http://www.esrf.eu/computing/scientific/FIT2D/). The deduced 1D diffractograms (intensity vs $2 \theta$ ) were analyzed with a full Rietveld refinement procedure. Diffraction peaks were modeled by pseudo-Voigt functions using FullProf software (https://www.ill.eu/sites/fullprof/) with 20 degrees of freedom for each record (background, phase fraction, lattice parameters, shape of peaks, and temperature effects).

On the experimental diffraction patterns, two phases can be identified and calibrated for certain. The first one is a face-centered cubic (fcc) phase corresponding to austenite. The second one is a body centered phase, close to a body centered cubic (bcc) lattice. This phase correspond either to martensite transforming during the initial and the final quench or to bainitic ferrite transforming 
during partitioning. The better resolution of the experiments conducted at DESY compared to our previous ones carried out at ESRF [9,13] have permitted to measure the mean tetragonal distortion of the lattice considering a body centered tetragonal (bct) lattice for the refinement procedure (better indexation criteria than using a bcc lattice). Nevertheless, the distinction has not been made between martensite and bainite contributions. As a consequence, only two phases have been taken into account in the Rietveld refinement procedure (Fm3m and $\mathrm{I} 4 / \mathrm{mmm}$ space groups). As in our previous experiments on a Fe-0.3C-2.5Mn-1.5Si-0.8Cr [9], weak peaks corresponding to $\eta$ carbides have been observed on diffraction patterns (precipitation during reheating at about $260{ }^{\circ} \mathrm{C}$ ). The precipitation of such carbides in Q\&P steels has already been suggested by Pierce et al. [15] on the basis of Mössbauer and Transmission Electron Microcopy experiments. This third phase was not quantified so far as the fraction remains below $1 \%$ and excluded from the refinement procedure.

Samples have been heat-treated in situ in a Bähr dilatometer. As compared to previous works, the Quench Temperature (QT) is $200{ }^{\circ} \mathrm{C}$ and the Partitioning Temperature (PT) is $400{ }^{\circ} \mathrm{C}$. This treatment permits to reach high fraction of martensite at QT and minimize the fraction of bainitic transformation at PT. The full austenitization have been performed at $900{ }^{\circ} \mathrm{C}$ during $5 \mathrm{~min}$. The cooling rate during initial quench is about $50^{\circ} \mathrm{C} / \mathrm{s}$ to avoid any ferritic or bainitic transformation. A $5 \mathrm{~s}$ isothermal step is followed at QT to guaranty a good thermal homogeneity in samples. The reheating rate is fixed at $30{ }^{\circ} \mathrm{C} / \mathrm{s}$. The partitioning time is about $200 \mathrm{~s}$ and the final cooling rate down to RT is about $50{ }^{\circ} \mathrm{C} / \mathrm{s}$. Figure 1.a shows examples of $1 \mathrm{D}$ diffractograms obtained by HEXRD for remarkable times along this thermal cycle. 

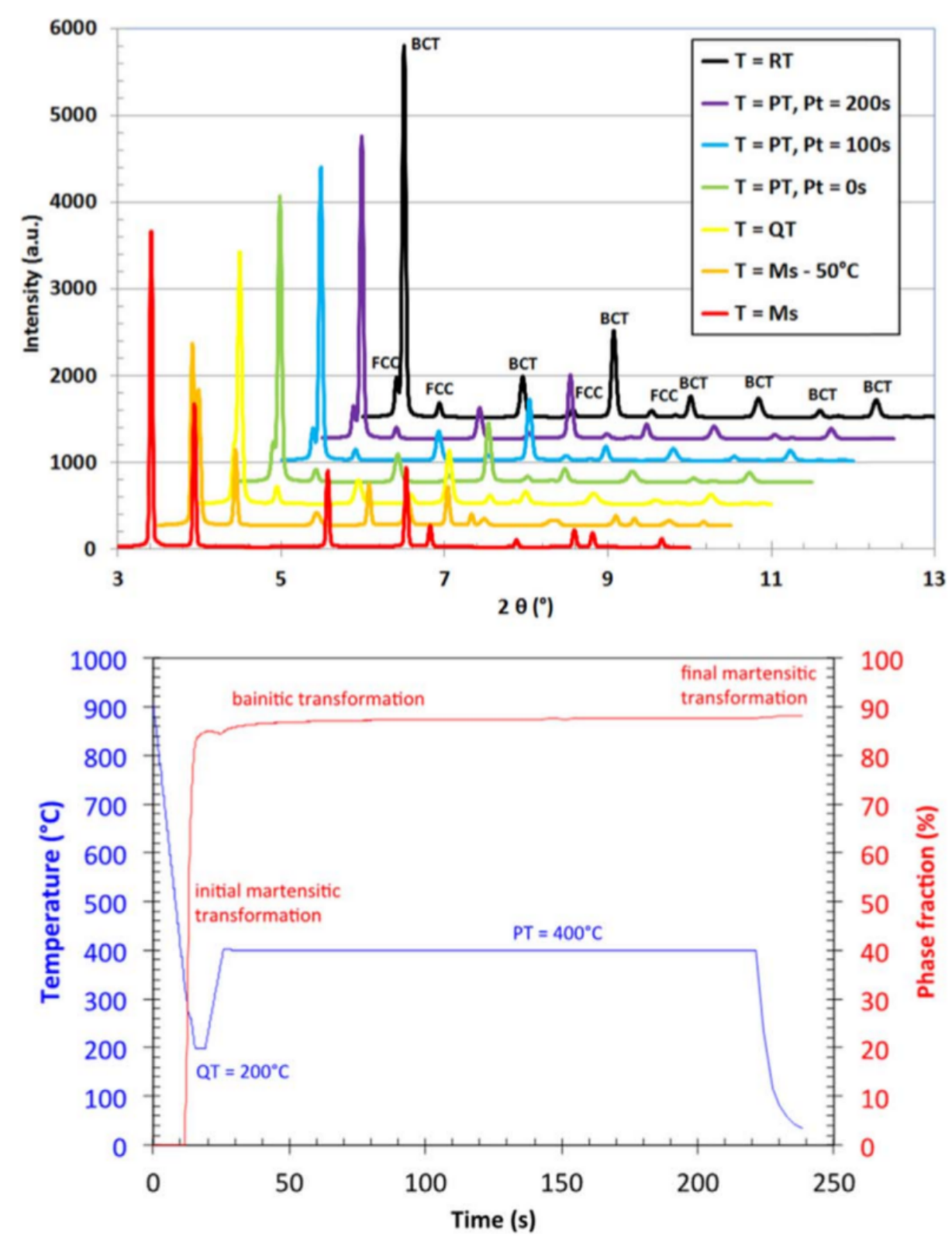

Figure 1: (a) 1D diffractograms (intensity vs 2 $\theta$ ) obtained at different characteristic times of the Q \& P process (at Ms, Ms-50 ${ }^{\circ} \mathrm{C}, \mathrm{QT}$, at the beginning, the middle and the end of partitioning step respectively and after final cooling at RT). The phases (FCC or BCT) explaining the main diffraction peaks have been indicated on the pattern corresponding to $\mathrm{T}=\mathrm{RT}$. The spectra have been offset from one another for readability reasons. (b) Evolution of temperature and of bct-phase fraction measured on diffractograms as a function of time measured along the cycle defined by QT $=200{ }^{\circ} \mathrm{C}$ and $\mathrm{PT}=400{ }^{\circ} \mathrm{C}$. The maximum error made on phase fraction measurements was about \pm $1 \%$. 


\section{Results:}

The temperature cycle followed for the experiment defined by QT $=200{ }^{\circ} \mathrm{C} / \mathrm{PT}=400{ }^{\circ} \mathrm{C}$ is represented in figure 1.b, as well as the bct-phase fraction deduced from the Rietveld refinement as function of time. The main phase transformations observed during the heat treatment have been reported, namely the martensitic transformations during initial (84\%) and final quenches (0.5\%) respectively and a bainitic transformation (3\%) during the partitioning step. The nature of these transformations has already been discussed in previous works and are similar to those reported on the Fe-0.3C-2.5Mn-1.5Si-0.8Cr steel [9,13]. The final fraction of retained austenite is thus $12.3 \%$ at room temperature (RT).

The figure 2 shows the evolution of austenite lattice parameter as a function of temperature measured along the same cycle. Between $900{ }^{\circ} \mathrm{C}$ and $320{ }^{\circ} \mathrm{C}$, prior to the first martensitic transformation, the alloy is fully austenitic with the nominal composition (assumed to be uniform after austenitization). The observed decrease in austenite lattice parameter is thus solely due to the thermal contraction in absence of internal stresses and composition changes. Van Bohemen has recently proposed an empirical temperature sensitive CTE for austenite $\left(\alpha^{\gamma}(T)\right)$ based on dilatometry experiments [11]:

$$
\alpha^{\gamma}(T)=B^{\gamma}\left(1-\exp \left(-T / \theta^{\gamma}\right)\right.
$$

with $\mathrm{B}^{\gamma}$ the value of the CTE at high temperature and $\theta^{\gamma}$ a critical temperature, two parameters which have been calibrated for austenite on highly alloyed steels (with low Ms temperatures) by Van Bohemen. In the present work, the proposed formalism was also used for austenite and recalibrated based on HEXRD measurements. The best fit has been obtained with $\mathrm{B}^{\mathrm{\gamma}}=2.53 \times 10^{-5}$ $\mathrm{K}^{-1}$ and $\theta^{\gamma}=250 \mathrm{~K}$. The $\mathrm{B}^{\gamma}$ value is consistent with the constant value proposed by Lu et al. [10]. The critical temperature $\theta^{r}$ is slightly lower than the value originally proposed by Van Bohemen (280 K) [11] who considered $\theta^{\gamma}$ as an adjustable parameter difficult to calibrate for certain. The evolution of the lattice parameter according to equation (1) is represented by the red curve in figure 2, showing the excellent experiment/model agreement down to the initial martensitic transformation $\left(\mathrm{Ms}=320^{\circ} \mathrm{C}\right.$ ). When integrating equation 1 to plot the red curve in figure 2 , the lattice parameter at $800{ }^{\circ} \mathrm{C}$ has been considered as an initial condition and has also been adjusted with a least square method on the experimental results. 


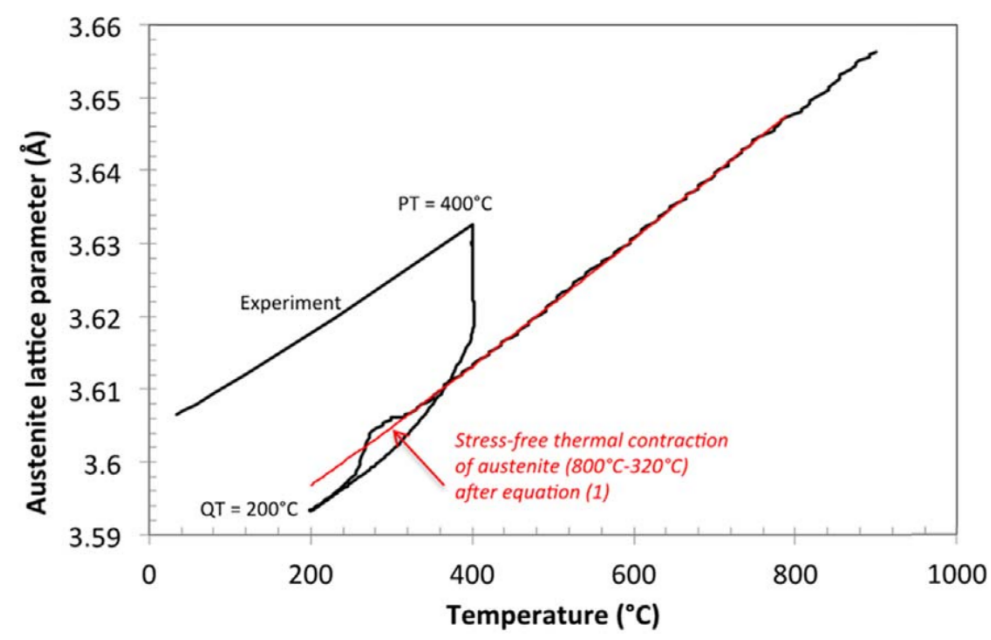

Figure 2: Black curve: Evolution of austenite lattice parameter as a function of temperature measured along the cycle defined by QT $=200{ }^{\circ} \mathrm{C}$ and PT $=400{ }^{\circ} \mathrm{C}$. Red curve: stress-free thermal contraction of austenite lattice parameter in the range $320-800{ }^{\circ} \mathrm{C}$ modeled with equation 1 .

Below Ms temperature, the lattice parameter deviates from the stress-free thermal contraction. It is first slightly larger than expected for a pure thermal behavior and then decreases suddenly. At QT, the lattice parameter is $3.34 \times 10^{-3} \AA$ lower than predicted by equation 1 . The inversion is obtained after about $55 \%$ of transformation. As the martensitic transformation occurs without diffusion, these deviations must be interpreted on the basis of second-order internal stresses, i.e. internal stresses at phase scale. Austenite undergoes first hydrostatic tensile stresses at the beginning of the martensitic transformation and then hydrostatic compressive stresses. At QT, the elastic lattice strain corresponds to a pressure of $-550 \mathrm{MPa}$ using a temperature /composition dependent model for elastic constants developed by Ghosh and Olson, assuming a shear modulus of austenite for the considered composition of $\mu^{\gamma}=75 \mathrm{GPa}$ at $\mathrm{T}=200{ }^{\circ} \mathrm{C}$ [16]. This stress value is slightly lower than the one determined in our previous work on a similar alloy (- $750 \mathrm{MPa}$ ) [9]. This measurement is thus extremely sensitive to the choice of the CTE function when extrapolated at low temperature. This sensitivity will be discussed later. The compressive stress states in austenite after extended martensitic transformation have already been reported in the literature [17-19], but never modeled so far to the knowledge of the authors.

At the very beginning of the reheating stage, it appears that the experimental CTE is lower than the stress-free CTE, as described by equation 1. The corresponding portion of figure 2 has been enlarged in figure 3 for a better readability. In fact, as the microstructure is mainly martensitic with residual austenite islands, and as martensite and austenite do not have the same CTE, austenite cannot expand freely when temperature increases. As a consequence, austenite is put into 
compression during reheating, and shows a lower apparent CTE. Different micromechanical frameworks based on Mori-Tanaka mean field assumptions [20,21] have been developed to predict the apparent CTE of a dilute composite knowing the respective behaviors of phases. The scheme followed in this work has been adapted from Lu [21]. As the contrast in elastic behaviors between martensite and austenite is weak, the virtual eigenstrains are close to the real one. Assuming spherical islands of austenite in a martensitic matrix, the constrained apparent CTE in austenite writes:

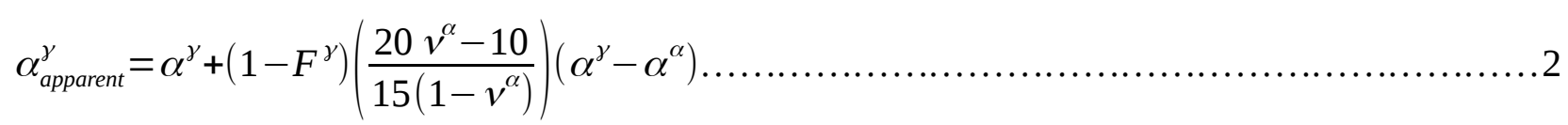

With $\mathrm{F}$ the fraction of austenite (in islands in the considered framework), $\mathrm{v}^{\alpha}$ the Poisson ratio of martensite and $\alpha^{\alpha}$ the stress-free CTE of martensite. The aspect ratio of the austenite islands has only a weak effect on the final result [21]. In equation 2, $\alpha^{\gamma}$ is given by equation 1 and $\alpha^{\alpha}$ is supposed to be the same as in ferrite, and has been modeled according to Van Bohemen [11]. The constrained thermal expansion of austenite predicted by equation 2 is represented by the blue curve in figure 3. The agreement between the model and the experiment is excellent from QT up to 260 ${ }^{\circ} \mathrm{C}$ during reheating. It must be mentioned that in our previous work [9], it has not been possible to conduct this refined analysis during reheating and consider this apparent CTE because of thermal heterogeneities in samples which have affected the experimental results.

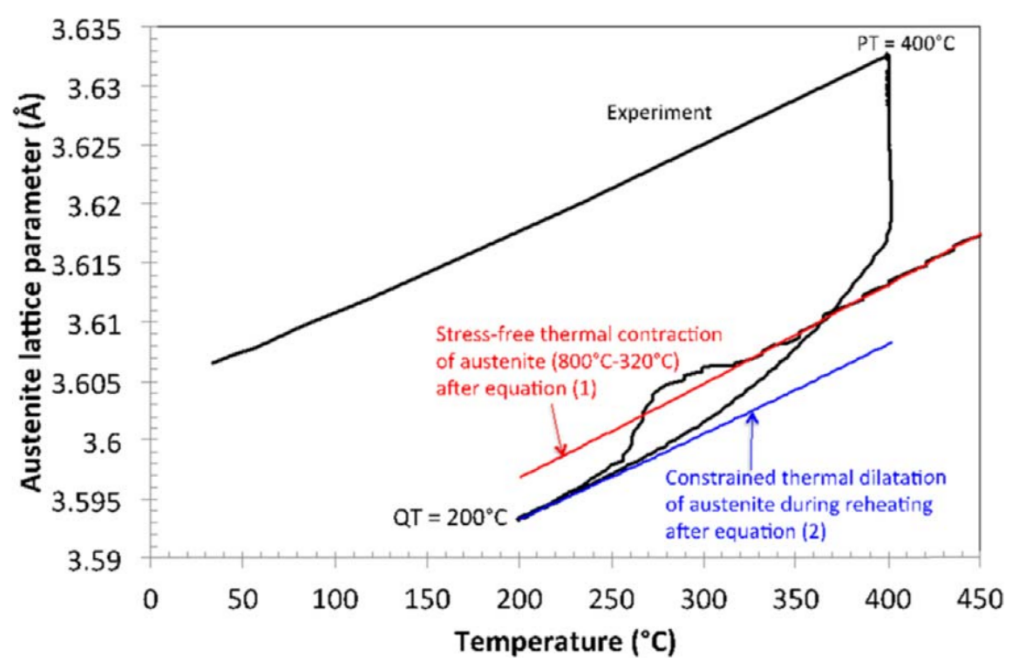

Figure 3: Enlargement of figure 2 in the low temperature range. Black curve: evolution of austenite lattice parameter as a function of temperature measured along the cycle. Red curve: stress-free thermal contraction of austenite lattice parameter in the range $320-800{ }^{\circ} \mathrm{C}$, according to equation 1 . Blue curve: constrained thermal dilatation of austenite during reheating, according to equation 2. 
Above $260{ }^{\circ} \mathrm{C}$, the experimental lattice parameter deviates from the expected constrained thermal dilatation represented by the blue curve in figure 3. This deviation is mainly explained by the carbon enrichment in austenite due to partitioning and to the carbide-free bainitic transformation (even if this is a minor contribution in the present cycle). As suggested by our prior works, the possible relaxation of compressive internal stresses cannot be definitively ruled out. However, the Full Width at Half Maximum (FWHM) of austenite diffraction peaks does not evolve significantly during reheating, and the kinetics of such processes are known to be too slow at PT $=400{ }^{\circ} \mathrm{C}$ compared to what is observed experimentally [22]. The relative carbon enrichment in austenite can be deduced when comparing the lattice parameter at the end of partitioning step and the expected lattice parameter at $\mathrm{PT}=400{ }^{\circ} \mathrm{C}$ according to equation 2 . In the present case, the increase in austenite lattice parameter due to carbon enrichment is $24.5 \times 10^{-3} \AA$ which corresponds to an increase in carbon content of $0.75 \%$ [9]. The final carbon content in austenite is thus $1.06 \%$ at the end of the partitioning step. This determination is only made possible by an accurate modeling of the constrained thermal dilatation during reheating. Indeed, the error on austenite lattice increase $\Delta \mathrm{a}^{\gamma}$ committed if mechanical contribution is not taken into account can be approximated from equations 1 and 2 as follows:

$$
\begin{aligned}
& \Delta a^{\gamma}=a^{\gamma}(P T)\left(\alpha_{\text {apparent }}^{\gamma}(P T)-\alpha^{\gamma}(P T)\right)(Q T-P T) \\
& \Delta a^{\gamma}=a^{\gamma}(P T)\left(1-F^{\gamma}\right)\left(\frac{20 v^{\alpha}-10}{15\left(1-v^{\alpha}\right)}\right)\left(\alpha_{\text {apparent }}^{\gamma}(P T)-\alpha^{\gamma}(P T)\right)(Q T-P T)
\end{aligned}
$$

with $\mathrm{a}^{\gamma}(\mathrm{T})$ the austenite lattice parameter at temperature $\mathrm{T}$. This possible error increases of course with the temperature difference between QT and PT. As a consequence, depending on both volume fraction and elastic properties of phases, the carbon content in austenite is underestimated if only the stress-free CTE is considered (cf. equation 1). It should be mentioned that composition sensitivity of the CTE has been neglected here in accordance with the work of Onink et al. [23]. The bainitic transformation occurring during partitioning is also expected to have a minor effect since the transformed fraction is relatively weak (3\%) for this QT condition.

During final cooling, the microstructure is again duplex (bct/fcc) and undergoes thermal eigenstrains due to the difference of CTE between phases in the absence of final martensitic transformation (only 0.5\%). The same model as discussed above has thus been applied. figure 4 shows the predicted evolution of the lattice parameter assuming a constrained thermal contraction of austenite during cooling according to equation 2 compared to the one assuming a stress-free thermal contraction according to equation 1 . This means that austenite undergoes additional tensile 
stresses during final cooling. The agreement between the experiment and the evolution predicted by equation 2 is indisputable even if it seems to slightly overestimate the experimental behavior. The hydrostatic pressure can be determined as follows:

$$
P=\left(1-F^{\gamma}\right)\left(\frac{2 \mu^{\gamma}\left(1+v^{\gamma}\right)}{1-2 v^{\gamma}}\right)\left(\frac{20 v^{\alpha}-10}{15\left(1-v^{\alpha}\right)}\right)\left(\alpha^{\gamma}-\alpha^{\alpha}\right) \Delta T
$$

with $\Delta \mathrm{T}$ the considered temperature variation (here $\Delta \mathrm{T}=\mathrm{RT}-\mathrm{PT}$ ), $\mu^{\mathrm{\gamma}}$ the shear modulus of austenite ( $\mu^{\gamma}=78 \mathrm{GPa}$ at RT for a carbon enriched austenite according to Ghosh and Olson model [16]) and $v^{\gamma}$ the Poisson ratio of austenite, taken equal to $v^{\alpha}$. The CTE functions are estimated at RT. The pressure calculated with equation 4 is about $+450 \mathrm{MPa}$ (tensile hydrostatic stresses) whereas the measurement is slightly lower (425 MPa) when considering the experimental deviation from equation 1 instead. This additional contribution to internal stresses thus permits compensating partially the large compressive stresses induced by martensitic transformations and thermal eigenstrains during reheating.

As the three mechanisms affecting the internal stresses in austenite are operative at different temperatures, the final state in austenite cannot be calculated by simply adding the stress values discussed above. A reliable way to assess this final state consists first in measuring the total increase in austenite lattice parameter at RT taking as a reference the extrapolation of the stress-free contraction of austenite at RT, i.e. considering equation 1 down to RT. The total increase $\left(20.5 \times 10^{-2}\right.$ $\AA$ measured in the studied case) encompasses both chemical and stress effects. The contribution due to carbon enrichment $\left(24.5 \times 10^{-3} \AA\right)$ must then be subtracted. It thus remains a difference of -4.0 $\times 10^{-2} \AA$ that should be explained by compressive hydrostatic stresses only. Considering $\mu^{\gamma}=78$ GPa for carbon enriched austenite at RT [16], the final pressure in austenite is thus estimated to be $670 \mathrm{MPa}$. 


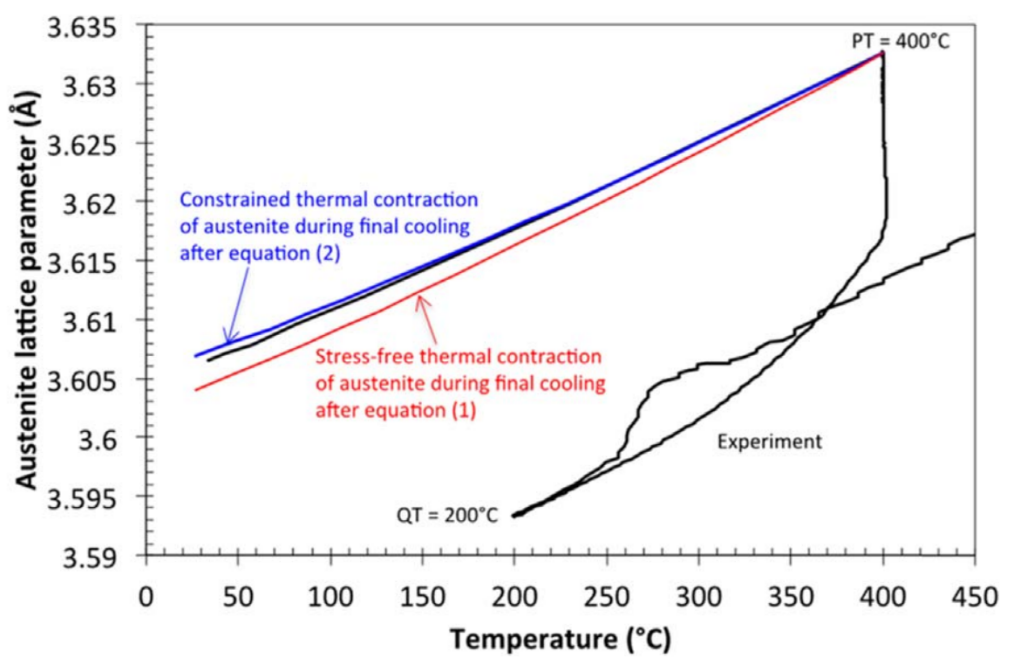

Figure 4: Enlargement of figure 2 in the low temperature range. Black curve: evolution of austenite lattice parameter as a function of temperature measured along the cycle. Red curve: stress-free thermal contraction of austenite lattice parameter expected during final cooling modeled according to equation 1. Blue curve: constrained thermal dilatation of austenite lattice parameter expected during final cooling modeled according to equation 2.

\section{Discussion:}

a. Stabilizing effect of compressive stresses in retained austenite:

Considering the three mechanical contributions discussed above (transformation strain and constrained dilatation and contraction compared to stress-free states), austenite is in compression at RT (about $\mathrm{P}=-670 \mathrm{MPa}$ ). These compressive internal stresses contribute to stabilize retained austenite against a possible strain-induced transformation [24-27]. This stabilizing effect is due to a decrease in available driving force for the transformation. As a consequence, retained austenite will also be more stable against a possible thermal martensitic transformation. A way to quantify this effect is to reassess the Ms temperature of austenite accounting for internal stresses. According to the seminal works of Patel and Cohen [24,25], the expected drop in Ms (temperature) due compressive internal stresses $\mathrm{P}$ in austenite $(\mathrm{P}<0)$ can be estimated as follows:

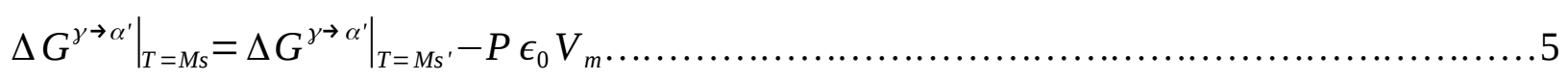

with $\Delta \mathrm{G}^{\mathrm{\gamma} \rightarrow \alpha}$ the Gibbs molar chemical free energy between austenite and martensite phases under no pressure at Ms and at Ms' (the apparent transformation start temperature under pressure $\mathrm{P}$ ). $\varepsilon_{0}$ is the volume change associated to the transformation and $\mathrm{V}_{\mathrm{m}}$ is the molar volume (taken here equal to $7.06 \times 10^{-6} \mathrm{~m}^{3} \mathrm{~mol}^{-1}$ ). The volume change associated to the martensitic transformation cannot be 
deduced from our experiment as this increase is strongly dependent on the carbon content of austenite [28]. The studied initial martensitic transformation represented in figure 1.b occurs in a low carbon austenite whereas the strain induced transformation at RT occurs in a high carbon austenite. In the following, we will use therefore the value $\varepsilon_{0}=3.7 \%$ suggested by Moyer et al. [28] for a Fe-1C model steel at RT. This value is consistent with the value of $2.98 \%$ chosen by Xie et al. [26] for a Fe-9Ni-1.4C alloy. The increase in Gibbs model free energy due to stress only under a pressure $\mathrm{P}=-670 \mathrm{MPa}$ is thus $-\mathrm{P} \varepsilon_{0} \mathrm{~V}_{\mathrm{m}}=175 \mathrm{~J} \mathrm{~mol}^{-1}$. As suggested by Perlade et al. [27], as a first estimate, the evolution in Gibbs molar chemical free energy with temperature is governed by the difference of entropies $\Delta S^{\gamma \rightarrow \alpha^{\prime}}$ between austenite and martensite (supposed constant). As a consequence, the difference between Ms and Ms' becomes:

$$
M s-M s^{\prime}=\frac{-P \epsilon_{0} V_{m}}{\Delta S^{\gamma \rightarrow \alpha^{\prime}}}
$$

Taking $\Delta \mathrm{S}^{\gamma \rightarrow \alpha^{\prime}}=6.8 \mathrm{~J} \mathrm{~mol}^{-1} \mathrm{~K}^{-1}$ as Perlade et al., the estimated decrease in Ms temperature due to the compressive hydrostatic stresses in austenite is about $25{ }^{\circ} \mathrm{C}$. This value is consistent with the values reported in others alloys and steels [24-26]. The linear sensitivity of the Ms temperature to pressure is thus $-0.037{ }^{\circ} \mathrm{C} \mathrm{MPa}^{-1}$. This value is not far from the one determined by Patel and Cohen $\left(-0.055^{\circ} \mathrm{C} \mathrm{MPa}^{-1}\right)$ for a Fe-30Ni alloy. In the studied steel, the stabilizing effect of internal stresses against a strain-induced transformation is thus equivalent to about an increase in carbon content of $0.06 \%$ at RT.

b. Sensitivity of the analysis to the CTE function:

The fact that austenite is shown to be in compression at RT appears to be in contradiction with the conclusions of our prior works [9]. The divergence is explained as we take into account in the present work the internal stresses induced during reheating prior to partitioning and as we have chosen to represent the stress-free CTE with an improved modeling. Both improvements lead to this new result. The conclusions derived from in situ experiments are thus highly sensitivity to the methodology and to the mathematical functions chose to represent reference states. These choices have not only consequences when determining the internal stresses in austenite but also when measuring the relative increase in austenite carbon content during partitioning (cf. equation 3) and when estimating the thermochemical stability of austenite. 
To sustain this discussion, the analysis of internal stresses and carbon enrichment has been conducted once more considering a constant CTE for austenite (as in our prior work). The function has been calibrated by a least square method on the experimental curve in figure 2 in the same temperature range as for equation 1 . The value found is $2.412 \times 10^{-5} \mathrm{~K}^{-1}$ which is also close to the value proposed by $\mathrm{Lu}$ et al. [10]. As suggested by Van Bohemen's analysis, the least square correlation is however worse than the one obtained previously with equation 1 . The values of stresses and carbon enrichment deduced with this simpler CTE function have been summarized in Table 1 and compared to the values obtained in the previous sections.

Table 1: Comparison between the values of hydrostatic stresses and carbon enrichment in austenite during the Q\&P treatment estimated either with a temperature dependent CTE (equation 1) as explained in the results section or with a constant CTE.

\begin{tabular}{|l|c|c|}
\hline & $\begin{array}{c}\text { Temperature dependent } \\
\text { CTE according to equation } \\
(1)\end{array}$ & $\begin{array}{c}\text { Constant CTE }\left(\alpha^{\gamma}=\right. \\
\left.2.412 \times 10^{-5} \mathrm{~K}^{-1}\right)\end{array}$ \\
\hline $\begin{array}{l}\text { Hydrostatic stresses in austenite after martensitic } \\
\text { transformation at } 200{ }^{\circ} \mathrm{C}\end{array}$ & $-550 \mathrm{MPa}$ & $-380 \mathrm{MPa}$ \\
\hline Absolute increase in carbon content during partitioning & $0.75 \%$ & $0.72 \%$ \\
\hline Hydrostatic stresses induced by final cooling at RT (equation 4) & $+450 \mathrm{MPa}$ & $+880 \mathrm{MPa}$ \\
\hline Final hydrostatic stresses in austenite at RT & $-670 \mathrm{MPa}$ & $+250 \mathrm{MPa}$ \\
\hline
\end{tabular}

Assuming a constant CTE, the estimated values of the hydrostatic stresses due to martensitic transformation are lower as already discussed in the result section. On the contrary, the values for eigenstresses induced by final cooling are higher. The slight curvature in the constrained contraction of austenite at low temperature which is well captured with the temperature dependent CTE (equation 2 represented in figure 4) cannot be however well reproduced with a constant CTE. This observation thus confirms the interest of using Van Bohemen's assumption at low temperature. As a consequence, always under this too simple assumption (constant CTE), final hydrostatic stresses in austenite at RT should be positive (tensile state), as reported in [9]. On the other hand, the measure of carbon enrichment is not affected so much by the choice of the CTE function when comparing both assumptions.

In the studied steels, Van Bohemen's description must thus be preferred as it allows a better description of stress-free austenite above Ms and also below Ms when considering the slight curvature of the constrained austenite contraction below PT. 


\section{Conclusion:}

We report the first in-situ high energy X-Ray diffraction experiments on the measurement of both carbon enrichment and internal stresses in austenite all along the processing route of a Q\&P steel (including quenching, reheating and final cooling steps). This ultra-fast resolved quantitative information coupled with calculations based mainly on both micromechanical approach and improved CTE description leads to the following conclusions:

- The internal stresses in austenite result from the hydrostatic compressive stress state in austenite induced by the initial martensite transformation below Ms and from the thermal eigenstrains induced by the difference of CTE between martensite and austenite during reheating and final cooling,

- Retained austenite is shown to be in compression at RT (about P =- $670 \mathrm{MPa}$ ). The determination of both the internal stresses and the relative increase of carbon content in austenite depend strongly on the temperature dependent CTE function,

- The compressive internal stresses in austenite are shown to stabilize retained austenite against a possible strain induced transformation at RT. The associated decrease in Ms temperature of constrained austenite is estimated around $25{ }^{\circ} \mathrm{C}$ in the studied steels. It corresponds to an equivalent increase in carbon content in austenite of about $0.06 \%$.

Finally, this study highlights that internal stresses generated all along the processing route of Q\&P steels affect the way to measure the carbon content in austenite, the carbon content in austenite, the stability of retained austenite at room temperature and thus the mechanical properties.

\section{Acknowledgements:}

This work was supported by the French State through the project CAPNANO (ANR-14-CE070029) operated by the National Research Agency (ANR). The synchrotron experiments were realized in December 2016, under the P160 grant at DESY PETRA P-07 in Hamburg, which is fully acknowledged. The authors would like also to thank MATERIALIA cluster and the LABEX DAMAS (ANR-11-LABX-0008-01) from Lorraine for their support. 


\section{References:}

[1] J.G. Speer, D.V. Edmonds, F.C. Rizzo, D.K. Matlock, Partitioning of carbon from supersaturated plates of ferrite, with application to steel processing and fundamentals of the bainite transformation, Curr. Opin. Solid State Mater. Sci. 8 (2004) 219-237.

[2] J.G. Speer, D.K. Matlock, B.C. De Cooman, J.G. Schroth, Carbon partitioning into austenite after martensite transformation, Acta Mater. 51 (2003) 2611-2622.

[3] D.V. Edmonds, K. He, F.C. Rizzo, B.C. De Cooman, D.K. Matlock, J.G. Speer, Quenching and partitioning martensite-a novel steel heat treatment, Mater. Sci. Eng. A 438-400 (2006) 25-34.

[4] E. De Moor, S. Lacroix, A.J. Clarke, J. Penning, J.G. Speer, Effect of retained austenite stabilized via quench and partitioning on the strain hardening of martensitic steels, Metall. Mater. Trans. A 39 (2008) 2586.

[5] E. De Moor, J.G. Speer, D.K. Matlock, J.H. Kwak, S.B. Lee, Effect of carbon and manganese on the quenching and partitioning response of CMnSi steels, ISIJ Int. 51 (2011) 137-144.

[6] X.C. Xiong, B. Chen, M.X. Huang, J.F. Wang, L. Wang, The effect of morphology on the stability of retained austenite in a quenched and partitioned steel, Scr. Mater. 68 (2013) 321-324.

[7] E.A. Ariza, A.S. Nishikawa, H. Goldenstein, A.P. Tschiptschin, Characterization and methodology for calculating the mechanical properties of a TRIP-steel submitted to hot stamping and quenching and partitioning (Q \& P), Mater. Sci. Eng. A 671 (2016) 54-69.

[8] T.D. Bigg, D.V. Edmonds, E.S. Eardley, Real-time structural analysis of quenching and partitioning (Q \& P) in an experimental martensitic steel, J. Alloy. Compd. 577S (2013) S695S698.

[9] S.Y.P. Allain, G. Geandier, J.C. Hell, M. Soler, F. Danoix, M. Gouné, Effects of Q\&P processing conditions on austenite carbon enrichment studied by In situ high-energy X-ray diffraction experiments, Metals 7 (2017) 232-245.

[10] X.G. Lu, M. Selleby, B. Sundman, Assessments of molar volume and thermal expansion for selected bcc, fcc and hcp metallic elements, Calphad 29 (2005) 68-89.

[11] S.M.C. Van Bohemen, The nonlinear lattice expansion of iron alloys in the range 100-1600 K, Scr. Mater. 69 (2013) 315-318.

[12] V.A. Esin, B. Denand, Q. Le Bihan, M. Dehmas, J. Teixeira, G. Geandier, S. Denis, T. Sourmail, E. Aeby-Gautier, In situ synchrotron X-ray diffraction and dilatometric study of austenite formation in a multi-component steel: influence of initial microstructure and heating rate, Acta Mater. 80 (2014) 118-131.

[13] S.Y.P. Allain, G. Geandier, J.C. Hell, M. Soler, F. Danoix, M. Gouné, In-situ investigation of quenching and partitioning by high energy X-ray diffraction experiments, Scr. Mater. 131 (2017) 15-18. 
[14] S.M.C. Van Bohemen, Bainite and martensite start temperature calculated with exponential carbon dependence, Mater. Sci. Technol. 28 (2012) 487-495.

[15] D.T. Pierce, D.R. Coughlin, D.L. Williamson, K.D. Clarke, A.J. Clarke, J.G. Speer, E. De Moor, Characterization of transition carbides in quench and partitioned steel microstructures by Mössbauer spectroscopy and complementary techniques, Acta Mater. 90 (2015) 417-430.

[16] G. Ghosh, G.B. Olson, The isotropic shear modulus of multicomponent Fe-base solid solutions, Acta Mater. 50 (2002) 2655-2675.

[17] N. Nakada, Y. Ishibashi, T. Tsuchiyama, S. Takaki, Self-stabilization of untransformed austenite by hydrostatic pressure via martensitic transformation, Acta Mater. 110 (2016) 95-102.

[18] Y. Tanaka, K. Shimizu, Anomalous changes in austenite and martensite lattice parameters of Fe-Mn-C alloys, Trans. Jpn. Inst. Met. 21 (1980) 42-50.

[19] M. Villa, K. Pantleon, M.A.J. Somers, In situ investigation of the martensitic transformation in Fe-12 wt\% Ni-0.6 wt\% C steel at subzero temperatures, J. Alloy. Compd. 577 (2013) 543-548.

[20] R.J. Arsenault, M. Taya, Thermal residual stress in metal matrix composite, Acta Metall. 35 (1987) 651-659.

[21] P. Lu, Further studies on Mori-Tanaka models for thermal expansion coefficients of composites, Polymer 54 (2013) 1691-1699.

[22] M.J. Manjoine, H.R. Voorhees, Compilation of Stress-Relaxation Data for Engineering Alloy, ASTM Data Series, Publication DS 60, ASTM International, West Conshohocken, PA, USA, 1982.

[23] M. Onink, C.M. Brakrnan, F.D. Tichelaar, E.J. Mittemeijer, S. Van der Zwaag, The lattice parameters of austenite and ferrite in Fe-C alloys as functions of carbon concentration and temperature, Scr. Metall. Mater. 29 (1993) 1011-1016.

[24] J.R. Patel, M. Cohen, Criterion for the action of applied stress in the martensitic transformation, Acta Metall. 1 (1953) 531-538.

[25] T. Kakeshita, T. Saburi, K. Shimizu, Effects of hydrostatic pressure and magnetic field on martensitic transformations, Mater. Sci. Eng. A 273-275 (1999) 21-39.

[26] Z.L. Xie, Y. Liu, H. Hänninen, Stabilization of retained austenite due to partial martensitic transformations, Acta Metall. Mater. 42 (12) (1994) 4117-4133.

[27] A. Perlade, O. Bouaziz, Q. Furnemont, A physically based model for TRIP-aided carbon steels behaviour, Mater. Sci. Eng. A 356 (2003) 145-152.

[28] J.M. Moyer, G.S. Ansell, The volume expansion accompanying the martensite transformation in iron-carbon alloys, Metall. Mater. Trans. A 6 (1974) 1785-1791. 